\title{
Can the complications of distal locking be prevented with a new nail that offers a novel locking technique in the treatment of humeral shaft fractures?
}

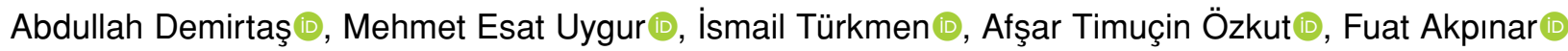 \\ Department of Orthopedics and Traumatology, Istanbul Medeniyet University, Göztepe Training and Research Hospital, Istanbul, Turkey
}

The popularity of intramedullary nails in the treatment of humerus fractures is increasing not only due to having the ability to share the load of the bone, but also because they can be applied by closed or mini open method and can reduce blood loss, radial nerve damage, operation time, hospitalization time, and union time. ${ }^{[1-6]}$ However, difficulty of advancement of the nail and iatrogenic fracture can be seen during intramedullary nailing in distal fractures due to narrowing of medulla. Additionally, prolongation of operation time, difficulty or failure in locking, neurovascular and other soft tissue damage, hemorrhage, and radiation exposure due to use of fluoroscopy may be encountered during distal locking. During postoperative follow-up, complications such as infection, screw loosening, migration, and irritation can be encountered as distal locking problems. ${ }^{[3,7,8]}$

Received: December, 2019

Accepted: March 08, 2020

Published online: September 11, 2020

Correspondence: Afşar Timuçin Özkut, MD. İstanbul Medeniyet Üniversitesi Göztepe Eğitim ve Araştırma Hastanesi Ortopedi ve Travmatoloji Kliniği, 34722 Kadıköy, İstanbul, Türkiye.

E-mail: afsarozkut@superonline.com

Doi: 10.5606/ehc. 2020.72963

Citation: Demirtas A, Uygur ME, Türkmen I, Özkut AT, Akpınar F. Can the complications of distal locking be prevented with a new nail that offers a novel locking technique in the treatment of humeral shaft fractures? Jt Dis Relat Surg 2020;31(3):470-475

(92020 All right reserved by the Turkish Joint Diseases Foundation

This is an open access article under the terms of the Creative Commons Attribution-NonCommercial License, which permits use, distribution and reproduction in any medium, provided the original work is properly cited and is not used for commercial purposes (http://creativecommons.org/licenses/by-nc/4.0/).

\section{ABSTRACT}

Objectives: This study aims to investigate whether complications related to distal locking can be prevented with InSafeLOCK ${ }^{\circledR}$ nail in the treatment of humeral shaft fractures.

Patients and methods: Hospital records of 31 patients (15 males, 16 females; mean age $54.4 \pm 10.1$ years; range, 20 to 86 years) treated with InSafeLOCK ${ }^{\circledast}$ nail for humeral shaft fractures were investigated retrospectively between February 2016 and January 2019. AO (Arbeitsgemeinschaft für Osteosynthesefragen) classification was used to determine the type of fracture. During the implementation, the elapsed time for distal locking was investigated. Complications encountered during both implementation and postoperative follow-up were investigated.

Results: Fourteen of the fractures were type A, 12 were type $\mathrm{B}$, and five were type $\mathrm{C}$. The mean follow-up time was 18.2 (range, 6 to 30.5) months. The mean duration for distal locking was 2.1 (range, 1.2 to 3.1 ) minutes. In one (3.2\%) patient, cortical penetration occurred at the anterior cortex of the humerus at distal to the nail. In one patient, nail breakage occurred at the distal part of the nail. In one patient, rotational instability occurred due to screw loosening.

Conclusion: InSafeLOCK ${ }^{\circledR}$ humeral nail is safe when applied with the recommended technique. It can easily be applied without damaging the veins, nerves or other soft tissues around the elbow due to the internal distal locking feature; furthermore, there is no need to use fluoroscopy or targeting guide. Thus, it is possible to avoid complications that may occur during and after distal locking in conventional intramedullary nail implementations.

Keywords: Complications, distal locking, humerus fracture, intramedullary nailing, neurovascular injury.

InSafeLOCK ${ }^{\circledR}$ nail (TST Tibbi Aletler San. ve Tic. Ltd. Sti., Istanbul, Turkey) is a new design nailing system developed to eliminate or minimize the problems related with distal locking in conventional interlocking nails. Although anatomic cadaver and biomechanical studies have been carried out using InSafeLOCK ${ }^{\circledR}$ nail, a clinical study has not been 
conducted..$^{[9,10]}$ Therefore, in this study, we aimed to investigate whether complications related to distal locking can be prevented with InSafeLOCK ${ }^{\circledR}$ nail in the treatment of humeral shaft fractures. ${ }^{[1]]}$

\section{PATIENTS AND METHODS}

Between February 2016 and January 2019, 40 patients with humeral shaft fracture treated with InSafeLOCK ${ }^{\circledR}$ intramedullary locking nail were evaluated retrospectively at Department of Orthopedics and Traumatology, Istanbul Medeniyet University, Göztepe Training and Research Hospital. Patients younger than 18 years of age were excluded and those who had at least six months of follow-up were included. Surgical indications were fractures with more than $20^{\circ}$ anterior angulation, more than $30^{\circ}$ varus/valgus angulation, more than $3 \mathrm{~cm}$ shortening, ipsilateral extremity fractures, segmental fractures, polytrauma, pathological fractures, nonunion and/or loss of reduction during conservative treatment and nonunion and/or implant failure after initial surgery. Fractures that extended from surgical neck to $4-5 \mathrm{~cm}$ proximal to olecranon fossa were included. Thus, 31 patients ( 15 males, 16 females; mean age $54.4 \pm 10.1$ years; range, 20 to 86 years) were included. All patients included met these criteria (Figure 1a, b). The study protocol was approved by the Medeniyet University Ethics Committee (Date: December 05, 2017; No: 2017/0348). A written informed consent was obtained from each patient. The study was conducted in accordance with the principles of the Declaration of Helsinki.

AO (A rbeitsgemeinschaft für Osteosynthesefragen) classification was used to

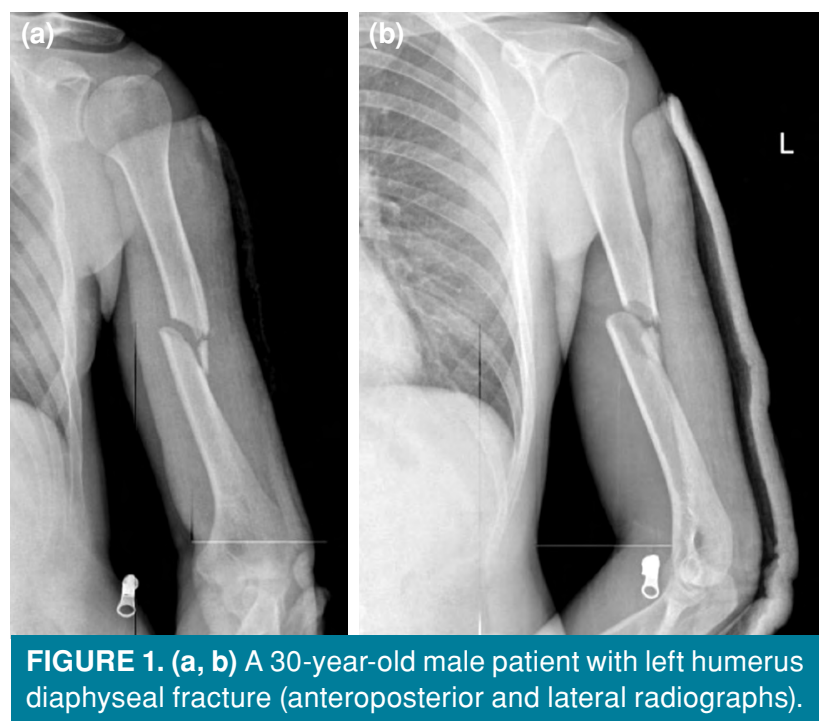

determine the type of fracture (Table I). GustiloAnderson (GA) classification was used for the classification of open fractures. In the initial treatment of open fractures, first generation cephalosporin group antibiotics were applied for infection prophylaxis and the wound was closed with sterile dressing after irrigation and debridement.

The patients were operated in beach chair position under general anesthesia. An incision of approximately 3-4 cm was performed at the anterolateral aspect of the acromion. First, the deltoid muscle and then the supraspinatus muscle were incised in line with the fibers and the humeral head was reached. Since InSafeLOCK ${ }^{\circledast}$ nail is a straight nail, the apex point of the humerus head (central entrance) was targeted as the nail entry hole. The nail entry hole was broadened using the reamer on the Kirschner wire (K-wire) applied intramedullarily from the nail entry site. The reduction of the fracture line was obtained under the guidance of fluoroscopy (by open method in six patients and closed method in 25 patients). The intramedullary guidewire was introduced until upper part of the olecranon fossa. None of the patients were reamed except one who was operated because of nonunion. After the sizes of the nails were determined, the chosen nail was inserted via the intramedullary $\mathrm{K}$-wire in the channel while distal curve of the nail was at anterior. After the nail was introduced distally, the guidewire was removed. Subsequently, distal locking procedure was started. The elbow was flexed

\begin{tabular}{|c|c|c|}
\hline \multicolumn{3}{|c|}{$\begin{array}{c}\text { TABLE I } \\
\text { Number of fractures according to AO classification }\end{array}$} \\
\hline Fracture type & Subtype & Number \\
\hline \multirow{4}{*}{ A } & 1.1 & 4 \\
\hline & 1.2 & 2 \\
\hline & 3.1 & 2 \\
\hline & 3.2 & 6 \\
\hline \multirow{5}{*}{ B } & 1.1 & 2 \\
\hline & 1.2 & 5 \\
\hline & 1.3 & 1 \\
\hline & 2.2 & 3 \\
\hline & 3.1 & 1 \\
\hline \multirow{4}{*}{ C } & 1.3 & 1 \\
\hline & 2.2 & 1 \\
\hline & 3.1 & 2 \\
\hline & 3.2 & 1 \\
\hline Total & & 31 \\
\hline
\end{tabular}



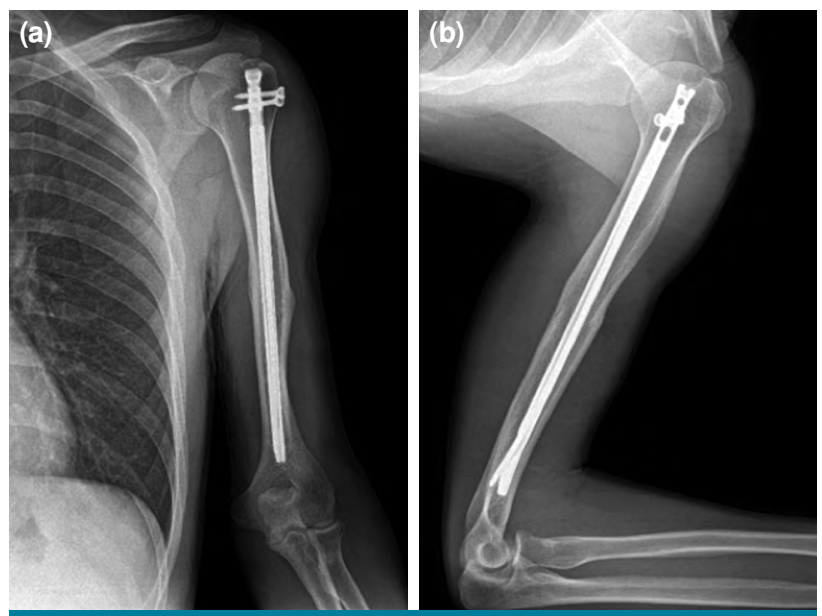

FIGURE 2. (a, b) Anteroposterior and lateral radiographs of same patient at postoperative 17.5 months.

$90^{\circ}$ while the forearm was supine before the internally safe locking pin screw (TST Tibbi Aletler San. ve Tic. Ltd. Sti., Istanbul, Turkey) was introduced. Lateral side of the nail holder was aimed at the lateral epicondyle. The distal-posterior cortex was drilled with the help of a 3×400 mm K-wire using a surgical motor. The Endopin was sent into the nail channel by its special screwdriver $(2.5 \times 200 \mathrm{~mm})$. The Endopin was advanced distally by rotating its screwdriver clockwise and inserted in the posterior cortex. Thus, distal locking was achieved both by inserting the threaded end of the Endopin into the posterior cortex and by compressing the distal end of the nail to the anterior. The elapsed time for distal locking was noted (from the moment when the K-wire was advanced to the nail channel until distal locking procedure was completed). Then, proximal locking procedure was carried out. Locking was performed through the targeting guide using at least one of the holes designed as static transverse, static angled, dynamic compression, and calcar screw for locking on the nail at the proximal. After the locking process was completed, supraspinatus tendon was re-sutured and the wound was closed.

First generation cephalosporin group antibiotics were administered for 24-48 hours for infection prophylaxis at the postoperative period. All patients' anteroposterior and lateral radiographs were evaluated in terms of reduction achievement and the situations of proximal screw(s) and Endopin (Figure 2a, b). Four patients had arm sling postoperatively, while two patients had long arm splint (one of them had forearm fracture and radial neuropathy, while the other had radial head fracture, coronoid fracture, and radial neuropathy). Except for these six patients, all patients were recommended to perform passive exercises for the shoulder, and active exercises for elbow and hand-wrist. Active shoulder mobility, and deltoid and rotator cuff strengthening exercises were started after six weeks. All patients were evaluated clinically and radiologically with respect to the complications associated with distal locking during their follow-up.

\section{RESULTS}

The mean follow-up time was 18.2 (range, 6 to 30.5) months. Twenty-eight fractures were closed, while three were GA type 1 open fractures. Three patients had head trauma, five had radial neuropathy, and eight had other bone fractures.

Twenty-four patients underwent primary surgical treatment. Of these, two had pathologic fractures on the basis of bone metastasis. Two patients were operated for implant failure. Five patients underwent conservative treatment at first; three patients underwent surgery after loss of reduction while two patients underwent surgery due to nonunion. Mean duration of surgery was 83.2 (range, 65 to 100) minutes. The mean time for distal locking was 2.1 (range, 1.2 to 3.1) minutes. Mean time to union was 100.3 (range, 86 to 140) days.

\begin{tabular}{|c|c|c|c|}
\hline \multicolumn{4}{|c|}{$\begin{array}{l}\text { TABLE II } \\
\text { Distal locking complications related with InSafeLOCK }{ }^{\circledR} \text { nail and predisposing factors }\end{array}$} \\
\hline Complications & $\mathrm{n}$ & $\%$ & Predisposing factors \\
\hline Distal cortical penetration & 1 & 3.2 & $\begin{array}{l}\text { Type of fracture: (AO-B1.3) } \\
\text { Narrow medulla } \\
\text { Technical error: Vigorous hammering }\end{array}$ \\
\hline Nail breakage & 1 & 3.2 & A new trauma during follow-up \\
\hline Rotational instability & 1 & 3.2 & $\begin{array}{l}\text { Serious osteoporosis: Instability due to screw loosening over } \\
\text { time despite insertion of Endopin into the distal posterior cortex }\end{array}$ \\
\hline
\end{tabular}


In one patient $(3.2 \%)$, cortical penetration occurred at the anterior cortex of the humerus at distal to the nail while the nail was introduced in the medullary canal. In one patient, nail breakage occurred at the distal part of the nail at postoperative $11^{\text {th }}$ month. In one patient, rotational instability occurred due to screw loosening. The predisposing factors for these complications are shown in Table II.

\section{DISCUSSION}

Intramedullary nails can be used primarily in the surgical treatment of many types of humeral fractures or secondary in nonunion cases. ${ }^{[3,5,12,13]}$ There are some studies that report shoulder dysfunction after humerus intramedullary nailing while these studies indicate that these problems are mostly related to chondral damage or prominent nail end..$^{[2,14]}$ Verdano et al. ${ }^{[15]}$ have evaluated shoulder ultrasound studies of patients with antegrade nailing and stated that there was no relationship between the rotator cuff tears and the subjective complaints of the patients. It has been shown that the incidence of postoperative problems related to rotator cuff irritation or tears was higher in bent nails than straight nails. ${ }^{[16]}$
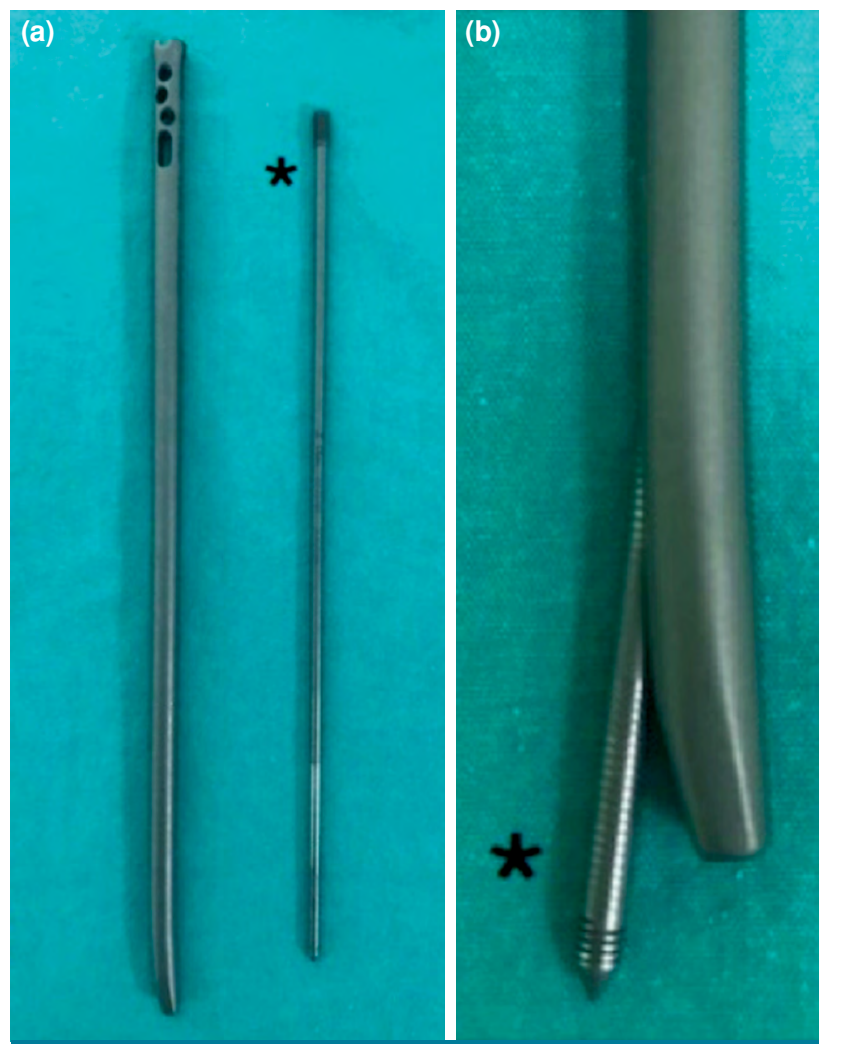

FIGURE 3. (a) InSafeLOCK ${ }^{\circledR}$ humerus nail and Endopin are demonstrated. (b) Endopin is mounted inside InSafeLOCK ${ }^{\circledR}$ nail.
In conventional nailing, the problems encountered related with distal locking have led the physicians to seek new solutions about distal locking. Conventional humerus nails' distal parts have flat endings. Complications such as difficulty in introducing the nail to the distal and iatrogenic fractures have been reported due to narrowing and anterior inclination of the medullary canal. ${ }^{[3,4,6]}$ Akpinar et al. ${ }^{[6]}$ examined humerus morphometry in cadaveric bones in point of view of intramedullary nailing. They reported that the medullary canal of the distal humerus was narrower than the proximal part. At the one third distal humerus, at a mean distance of $21 \mathrm{~cm}$ (range, 17 to $27 \mathrm{~cm}$ ) from the great tubercle, there was a mean anterior inclination of $9^{\circ}$ (range, 5 to $15^{\circ}$ ). They reported that the inclination and the anatomical features should be taken into consideration while advancing the flat nails distally during surgery. ${ }^{[6]}$ The distal tip of the InSafeLOCK ${ }^{\circledast}$ nail is designed to be compatible with the anterior inclination of the distal humerus..$^{[9,10]}$ Its $5^{\circ}$ anterior angulation of the distal end of the nail contributes to the rotational stability by both allowing the nail to reach the distal part of the medullary canal (up to $4-5 \mathrm{~cm}$ proximal to the olecranon fossa) and obtaining an offset into the medullary canal (Figure 2a, b and Figure 3). The most important difference from the conventional nails is that the distal locking can be performed inside-out by means of the special oval hole designed for the pin screw (Endopin) in the posterior aspect of the distal end of the nail (Figure 3). Drilling of posterior cortex and locking can be performed easily, rapidly, and safely without using fluoroscopy and skin incision. It is less painful and it promotes shorter duration of surgery. In our study, only one cortical penetration occurred at the anterior of the humerus at the distal of the nail during nail advancement. The fracture was at one third distal diaphyseal region (AO type B1.3) and the medullary canal of the female patient was markedly narrow in this area. The penetration occurred when the nail was tried to be inserted by hammering vigorously rather than advancing the nail by rotational movements and/or choosing a longer nail. We believe that InSafeLOCK ${ }^{\circledR}$ nail should be preferred in humerus fractures between surgical neck to the $4-5 \mathrm{~cm}$ proximal from olecranon fossa.

Neurovascular and/or tendon damage, breaking of the drill, and bleeding have been reported during the distal locking stage in the treatment of humeral shaft fractures with conventional nails. ${ }^{[3,7,8,17,18]}$ The distal humerus is rich in neurovascular anatomic structures; therefore, percutaneous distal locking 
may cause risks during conventional nailing. In their studies on cadaveric bones, Rupp et al. ${ }^{[19]}$ reported that the radial nerve is in direct risk in conventional nailing techniques where the distal locking is placed from lateral to medial in accordance with nail design. In case of excessive penetration of the medial cortex, the ulnar/median nerve and brachial artery are also at risk, and in the designs where anteroposterior locking is performed, the musculocutaneous nerve is at risk. Similarly, Baltov et al. ${ }^{[3]}$ reported that the risk rate of lateral antebrachial cutaneous nerve injury during distal locking is $1.8 \%$. In an anatomical study, Tasci et al. ${ }^{[9]}$ compared InSafeLOCK $^{\circledR}$ and Trigen ${ }^{\circledR}$ Humeral Nail (Smith \& Nephew, Memphis, TN, USA) nails on cadavers in terms of distance of the locking screws from the neurovascular structures. In their study, the average distance of the most distal screw in Trigen group was measured as $8.4 \mathrm{~mm}$ (range, 2 to $12 \mathrm{~mm}$ ) closer to the radial nerve, while in InSafeLOCK ${ }^{\circledR}$ nail, distal locking does not lead any risk of neurovascular injury due to leaning to the posterior. InSafeLOCK ${ }^{\circledast}$ nail was reported to be more reliable in terms of the risk of neurovascular injury. In our study, distal locking was performed safely in posterior cortex without the neurovascular damage, tendon damage, breaking of the drill or bleeding owing to the insideout locking system of the InSafeLOCK ${ }^{\circledR}$ nail.

In conventional nailing, the freehand technique for distal locking makes surgery difficult, while prolonging the duration and increasing radiation exposure. ${ }^{[8,9,17]}$ Electromagnetic guided targeting systems have been developed to reduce these problems in conventional nails. In the literature, there are few studies reporting the results of electromagnetic systems in patients who underwent intramedullary nailing for humerus fractures. ${ }^{[8,17,18]}$ Persiani et al. ${ }^{[8]}$ compared the electromagnetic system and freehand technique in terms of the time elapsed during the distal locking and exposure to radiation and the authors reported that the electromagnetic system significantly reduces the duration of distal locking and exposure to radiation, while causing additional cost. Antonini et al. ${ }^{[17]}$ reported an average distal locking time of 5.8 minutes for a single screw in their study using the electromagnetic system for humerus, femur, and tibia fractures. Camarda et al. ${ }^{[18]}$ compared the electromagnetic system with freehand technique for distal locking and they reported no significant difference between the two techniques in terms of total duration of surgery. Tasci et al. ${ }^{\left[{ }^{[0]}\right.}$ compared InSafeLOCK ${ }^{\circledR}$ and Trigen (Smith \& Nephew, Memphis, TN, USA) nails on cadavers in terms of the application durations. In their study, the mean distal locking duration was measured as 7.25 minutes for the most distal screw and 8.27 minutes for other distal screw in Trigen nail. On the other hand, the duration for distal locking was 2.37 minutes in InSafeLOCK ${ }^{\circledR}$ nail. In our study, the mean duration for distal locking was 2.1 minutes. This duration is consistent with the duration of the study of Tasci et al., ${ }^{[9]}$ and is quite shorter compared to the locking durations in both conventional nails and electromagnetic guided targeting system. Screw migration, irritation, and loosening are other complications that can be encountered in locking of the nails. ${ }^{[3,8,20]}$ Particularly, screw loosening is a major concern in the treatment of osteoporotic bones. However, Lin et al. ${ }^{[20]}$ reported that intramedullary nailing is an effective treatment method in cases of delayed union or nonunion in osteoporotic humeral fractures. In an in vitro study, Erden et al. ${ }^{[10]}$ reported that InSafeLOCK ${ }^{\circledR}$ nail has biomechanically adequate stability against axial and rotational loading. In our study, there was no screw migration-irritation during follow-up. However, rotational instability of the nail was observed over time around the distal part of the nail in a 76-year-old patient with serious osteoporosis who had a nonunion surgery after double plate osteosynthesis method.

The limitations of this study are the small number of patients, its retrospective design, and lack of comparison with other locking systems. More definitive results can be obtained with new prospective and comparative studies.

In conclusion, InSafeLOCK ${ }^{\circledast}$ nail is safe when applied with the recommended technique. It can be easily applied without damaging the veins, nerves or other soft tissues around the elbow due to the internal distal locking feature; furthermore, there is no need to use a locking guide for distal locking and use of fluoroscopy is diminished tremendously. In this way, it is possible to avoid complications that may occur during and after distal locking in conventional intramedullary nail applications.

\section{Declaration of conflicting interests}

The authors declared no conflicts of interest with respect to the authorship and/or publication of this article.

\section{Funding}

The authors received no financial support for the research and/or authorship of this article.

\section{REFERENCES}

1. Tsai CH, Fong YC, Chen $\mathrm{YH}, \mathrm{Hsu} \mathrm{CJ}$, Chang $\mathrm{CH}, \mathrm{Hsu} \mathrm{HC}$. The epidemiology of traumatic humeral shaft fractures in Taiwan. Int Orthop 2009;33:463-7.

2. Wali MG, Baba AN, Latoo IA, Bhat NA, Baba OK, Sharma S. Internal fixation of shaft humerus fractures by dynamic 
compression plate or interlocking intramedullary nail: a prospective, randomised study. Strategies Trauma Limb Reconstr 2014;9:133-40.

3. Baltov A, Mihail R, Dian E. Complications after interlocking intramedullary nailing of humeral shaft fractures. Injury 2014;45 Suppl 1:S9-S15.

4. Watson JT, Sanders RW. Controlled compression nailing for at risk humeral shaft fractures. J Orthop Trauma 2017;31 Suppl 6:S25-S8.

5. Janssen SJ, Bramer JAM, Guitton TG, Hornicek FJ, Schwab JH. Management of metastatic humeral fractures: Variations according to orthopedic subspecialty, tumor characteristics. Orthop Traumatol Surg Res 2018;104:59-65.

6. Akpinar F, Aydinlioğlu A, Tosun N, Doğan A, Tuncay I, Unal O. A morphometric study on the humerus for intramedullary fixation. Tohoku J Exp Med 2003;199:35-42.

7. Yi JW, Lee JS, Cho HJ. Retrograde intramedullary nailing for humerus fracture in a supine position: Performing an unfamiliar procedure in a familiar position. Clin Orthop Surg 2017;9:392-5.

8. Persiani P, Gurzi M, Moreschini O, Di Giacomo G, Villani C. Fluoroscopic freehand and electromagnetic-guided targeting system for distal locking screws of humeral intramedullary nail. Musculoskelet Surg 2017;101:19-23.

9. Tasci M, Turkmen İ, Celik H, Akcal MA, Şekerci R, Keles N, et al. InSafeLock humeral nail provides a safe application for proximal and distal locking screws with distal endopin - An anatomical study. Orthop Traumatol Surg Res 2019;105:1005-11.

10. Erden T, Kapicioglu M, Demirtas A, Bilsel K, Akpinar F, Kuduz H. Biomechanical comparison of humeral nails with different distal locking mechanisms: Insafelock nails versus conventional locking nails. Acta Orthop Traumatol Turc 2019;53:490-6.

11. Atik OŞ. Every new technique either conservative or surgical is good? Eklem Hastalik Cerrahisi 2019;30:183-4.
12. McCormack RG, Brien D, Buckley RE, McKee MD, Powell J, Schemitsch EH. Fixation of fractures of the shaft of the humerus by dynamic compression plate or intramedullary nail. A prospective, randomised trial. J Bone Joint Surg [Br] 2000;82:336-9.

13. Sügün TS, Ozaksar K, Toros T, Kayalar M, Bal E, Ozerkan F. Humeral shaft nonunions: plates and nails. Eklem Hastalik Cerrahisi 2012;23:150-5.

14. Bhandari M, Devereaux PJ, McKee MD, Schemitsch EH. Compression plating versus intramedullary nailing of humeral shaft fractures--a meta-analysis. Acta Orthop 2006;77:279-84.

15. Verdano MA, Pellegrini A, Schiavi P, Somenzi L, Concari G, Ceccarelli F. Humeral shaft fractures treated with antegrade intramedullary nailing: what are the consequences for the rotator cuff? Int Orthop 2013;37:2001-7.

16. Lopiz Y, Garcia-Coiradas J, Garcia-Fernandez C, Marco F. Proximal humerus nailing: a randomized clinical trial between curvilinear and straight nails. J Shoulder Elbow Surg 2014;23:369-76.

17. Antonini G, Stuflesser W, Crippa C, Touloupakis G. A distallock electromagnetic targeting device for intramedullary nailing: Suggestions and clinical experience. Chin J Traumatol 2016;19:358-61.

18. Camarda L, Zini S, Butera M, Giambartino S, Mattaliano $\mathrm{U}$, Raso F, et al. Electromagnetic distal targeting system does not reduce the overall operative time of the intramedullary nailing for humeral shaft fractures. J Orthop 2018;15:899-902.

19. Rupp RE, Chrissos MG, Ebraheim NA. The risk of neurovascular injury with distal locking screws of humeral intramedullary nails. Orthopedics 1996;19:593-5.

20. Lin J, Hou SM, Hang YS. Treatment of humeral shaft delayed unions and nonunions with humeral locked nails. J Trauma 2000;48:695-703. 